
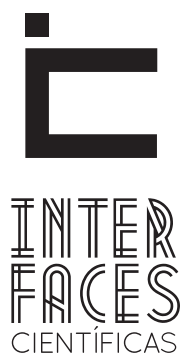

HUMANASE SOCIAIS

ISSN IMPRESSO 2316-3348

ISSN ELETRÔNICO 2316-3801

DOI 10.17564/2316-3801.2015v4n1p54-65

\title{
DILEMAS E IMPRECISÕES NA DEFINIÇÃO DAS COMPETÊNCIAS E DAS ATRIBUIÇÕES PRIVATIVAS DO SERVIÇO SOCIAL
}

Jonis Manhães Sales Felippe ${ }^{1}$

\section{RESUMO}

A partir da análise das leis de regulamentação do Serviço Social de 1957 e 1993, este artigo busca desvelar as conexões existentes entre a estrutura legal da profissão e a indefinição das tarefas específicas dos assistentes sociais, estas já sinalizadas por pesquisas da área e pelo CFESS. Para alcançar os objetivos propostos, também são analisadas e contrapostas as produções de importantes autores do Serviço Social que se dedicaram a refletir sobre os temas relacionados à legislação profissional, o que aponta para a construção de mais incertezas do que elucidações sobre o assunto.

\section{PALAVRAS-CHAVE}

Atribuições privativas. Legislação Profissional. Serviço Social. 


\section{ABSTRACT}

From the analysis of the regulatory laws of Social Work 1957 and 1993, this article seeks to reveal the connections between the legal profession structure and the lack of definition of specific tasks of social workers, these already signaled by research area and the CFESS. To achieve the proposed objectives, they are also analyzed and contrasted the productions of important authors of Social Work who have dedicated themselves to reflect on issues related to professional legislation, which aims to build more uncertainty than elucidations on the subject.

\section{KEYWORDS}

Exclusive Duties. Professional Legislation. Social Work.

\section{RESUMEN}

A partir del análisis de las leyes reguladoras del Trabajo Social de 1957 y 1993, este artículo trata de descubrir las conexiones existentes entre la estructura legal de la profesión y la indefinición de las tareas específicas de los asistentes sociales, estas ya señalados por investigaciones del área y por CFESS. Para lograr lo propuesto, también se analizan y contrastan las producciones de autores importantes del Trabajo Social, que se han dedicado a reflexionar sobre temas relacionados con la legislación profesional, lo que apunta para la construcción de más incertidumbres que aclaraciones sobre el tema.

\section{PALABRAS CLAVE}

Tareas privativas. Legislación profesional. Trabajo Social. 


\section{INTRODUÇÃO}

Segundo Nunes e Carvalho (2007), o Brasil possui atualmente cerca de quarenta e três profissões de nível superior regulamentadas, entre as quais se encontra a de assistente social. As leis que reconhecem tais ocupações, mais do que um simples dispositivo formal, são recursos que permitem a clarificação das competências e dos papéis das diversas categorias para os seus próprios membros, os demais profissionais e os empregadores (TORRES, 2007).

O principal papel das legislações é o de institucionalizar as atribuições e as tarefas inerentes ao trabalho dos profissionais. Em outras palavras, pode-se dizer que o instrumento jurídico garante legalmente reservas de mercado ou, ainda, de acordo com Diniz (2001, p. 65), monopólios de intervenção e prestação de serviços com base em credenciais educacionais.

No entanto, a análise detalhada das legislações e da produção acadêmica no âmbito do Serviço Social sinaliza que a atual regulamentação da profissão de assistente social no Brasil ainda possui importantes fragilidades, especialmente na definição das tarefas e atividades privativas desse profissional.

\section{A REGULAMENTAÇ̃̃O DO SERVIÇO SOCIAL NO BRASIL}

A Lei 3.252/57, regulamentada pelo Decreto $994 / 62$, foi o primeiro instrumento normativo a regulamentar a profissão no Brasil. Em seu texto, constam dois artigos $\left(2^{\circ}\right.$ e $\left.5^{\circ}\right)$ que estabelecem as tarefas específicas referentes ao trabalho do assistente social, versando em seu art. $1^{\circ}$ que "o Serviço Social constitui o objeto da profissão liberal de Assistência Social, de natureza técnico-científica” (BRASIL, 1962).

Considerando o propósito das leis de regulamentação das profissões apresentado por Torres (2007), algumas questões importantes já podem ser apontadas ao se avaliar a estrutura do texto da década de 1950. Dentro de um mesmo artigo - 50, o legislador utiliza termos como prerrogativas e atribuições (estas no parágrafo único), mas não estabelece claramente se se tratam de sinônimos. Dessa maneira, o instrumento jurídico leva à compreensão de que todas as atividades listadas neste artigo são exclusivas do assistente social, considerando que prerrogativa seria a "vantagem com que se distingue pessoa ou corporação; privilégio, regalia" e atribuição o "1. Ato ou efeito de atribuir; 2. Prerrogativa, privilégio; 3. Faculdade inerente a um cargo" (Dicionário Aurélio, 2001).

Desse modo, ao expor as atividades que cabem ao profissional de Serviço Social, a Lei de 1957, regulamentada pelo Decreto de 1962, dispõe o seguinte:

\begin{abstract}
Art. $2^{\circ}$ São atividades profissionais do Assistente Social aquelas cujo exercício determina a aplicação dos processos específicos de Serviço Social.

[...]

Art. $5^{\circ}$ São prerrogativas do Assistente Social:

I - Dirigir Escolas de Serviço Social;

II - Ensinar as cadeiras ou disciplinas de Serviço Social e supervisionar profissionais e alunos em trabalhos teóricos e práticos de Serviço Social;

III - Planejar e dirigir o Serviço Social, bem como executá-lo em órgão e estabelecimentos públicos autárquicos, paraestatais, de economia mista e particulares; IV- Assessorar técnicamente assuntos de Serviço Social nos órgãos e estabelecimentos públicos, autárquicos, paraestatais, de economia mista e particulares; V - Realizar perícias, judiciais ou não, e elaborar pareceres sôbre matéria de Serviço Social (BRASIL, 1962).
\end{abstract}

Como é possível perceber, o instrumento jurídico se utiliza de termos como matéria, processos específicos e assuntos de Serviço Social que em nada favorecem a compreensão das prerrogativas profissionais. O planejamento, a gestão, a assessoria e a realização de perícias e pareceres são funções compartilhadas por diversas categorias, de modo que necessitam da 
explicitação de mais elementos para que possam se constituir como privativas do Serviço Social.

Engana-se, porém, quem acredita que a legislação substitutiva de 1993, inaugurada num período em que a profissão promoveu um profundo redimensionamento de suas bases teóricas e políticas, avançou significativamente na delimitação das atividades específicas. Ainda que seja considerada por lamamoto (2012) como um dos pilares do projeto ético-político do Serviço Social na atualidade, a Lei 8.662/93 reproduziu as mesmas falhas do texto anterior e ainda acrescentou novas dubiedades e contradições ao tratar de algumas funções privativas.

Na concepção de Terra (1998), compartilhada por lamamoto (2012), embora juridicamente as competências e as atribuições possam ser tratadas como sinônimas, o legislador responsável pela elaboração da Lei 8.662/93 diferenciou essas duas palavras, conferindo um artigo do texto para cada uma delas. Dessa maneira, as competências passaram a se referir àquelas atividades a que o assistente social estaria habilitado a executar, mas que também poderiam ser realizadas por outros profissionais, sendo, portanto, genéricas (artigo $4^{\circ}$ ). Já as atribuições privativas (artigo $5^{\circ}$ ) seriam aquelas ações exclusivas do Serviço Social, que somente poderiam ser implementadas por pessoa devidamente qualificada e inscrita nos quadros do conselho de categoria (prerrogativas).

Nessa direção, é ilustrativo o inciso XI do art. $4^{\circ}$ da Lei de 1993, que estabelece como competência do assistente social "realizar estudos sócio-econômicos com os usuários para fins de benefícios e serviços sociais junto a órgãos da administração pública direta e indireta, empresas privadas e outras entidades" (BRASIL, 1993). Essa atividade é uma das poucas que possui delimitação clara, uma vez que determina a tarefa (realização de estudos socioeconômicos), a finalidade (inclusão em benefícios e serviços sociais) e o espaço de execução (órgãos da administração pública direta e indireta, empresas privadas e outras entidades).
Contudo, como identificou Terra (1998), trata-se de uma atribuição historicamente realizada apenas por assistentes sociais, mas que, por equívoco do texto legal, permanece no campo das competências (podendo - legalmente falando - ser executada por qualquer outro profissional). 0 mesmo poderia ser observado em relação ao inciso III, no qual consta uma competência que, segundo Terra (Idem), seria também uma tarefa privativa: "encaminhar providências, e prestar orientação social a indivíduos, grupos e à população" (BRASIL, 1993).

Não obstante, o encaminhamento de providências e a orientação social de per si não configuram monopólios do Serviço Social, pois são tarefas muito vagas, que necessitariam de maior explicitação para serem incluídas no artigo 5. 0 parecer de Terra (1998, p. 7) acrescenta que a "orientação social a indivíduos, grupos e a população é função privativa do assistente social, desde que inserida no âmbito das funções do Serviço Social e como parte do processo da utilização dos métodos e técnicas do Serviço Social”. De forma alguma essa complementação proposta pela assessora jurídica do CFESS (Conselho Federal de Serviço Social) esclareceria o problema, uma vez que levaria à repetição das mesmas imprecisões que podem ser visualizadas no conjunto das atribuições previstas nos artigos $2^{\circ}$ e $5^{\circ}$ da Lei de 3.252 de 1957, regulamentada pelo Decreto 994 de 1962, e também daquelas inscritas nos incisos do artigo $5^{\circ}$ da Lei 8662/93 (BRASIL, 1993), como se pode observar abaixo:

\footnotetext{
Art. $5^{\circ}$ Constituem atribuições privativas do Assistente social:

I - coordenar, elaborar, executar, supervisionar e avaliar estudos, pesquisas, planos, programas e projetos na área de Serviço Social;

II - planejar, organizar e administrar programas e projetos em Unidade de Serviço Social;

III - assessoria e consultoria e órgãos da Administração Pública direta e indireta, empresas privadas e outras entidades, em matéria de Serviço Social;

IV - realizar vistorias, perícias técnicas, laudos periciais, informações e pareceres sobre a matéria de Serviço Social;

V - assumir, no magistério de Serviço Social tanto a
} 
nível de graduação como pós-graduação, disciplinas e funções que exijam conhecimentos próprios e adquiridos em curso de formação regular;

VI - treinamento, avaliação e supervisão direta de estagiários de Serviço Social;

VII - dirigir e coordenar Unidades de Ensino e Cursos de Serviço Social, de graduação e pós-graduação;

VIII - dirigir e coordenar associações, núcleos, centros de estudo e de pesquisa em Serviço Social;

IX - elaborar provas, presidir e compor bancas de exames e comissões julgadoras de concursos ou outras formas de seleção para Assistentes Sociais, ou onde sejam aferidos conhecimentos inerentes ao Serviço Social;

$X$ - coordenar seminários, encontros, congressos e eventos assemelhados sobre assuntos de Serviço Social;

XI - fiscalizar o exercício profissional através dos Conselhos Federal e Regionais;

XII - dirigir serviços técnicos de Serviço Social em entidades públicas ou privadas;

XIII - ocupar cargos e funções de direção e fiscalização da gestão financeira em órgãos e entidades representativas da categoria profissional.

Como se verifica na Lei atual, esses seriam, em tese, os monopólios de prestação de serviço ou as tarefas específicas do assistente social. Entretanto, acompanhando os grifos, é possível perceber que, do mesmo modo como no texto de 1957, as expressões que possibilitariam diferenciar as atividades comuns às diversas ocupações - administração, assessoria, planejamento, realização de perícias e laudos, entre outras - daquelas específicas do assistente social continuam obscurecidas pelos termos matéria, área, unidade de Serviço Social.

A análise do art. $5^{\circ}$ relativo às atribuições privativas do Assistente Social, especialmente os incisos de I a IV, indica que a maior dificuldade na identificação desse caráter privativo não se encontra na descrição ou relato da atividade a ser desenvolvida, que em si mesma não é prerrogativa de qualquer profissional em particular, como, por exemplo: coordenar, elaborar, executar, supervisionar e avaliar estudos, pesquisas e projetos; planejar, organizar é administrar projetos; realizar assessoria e consultoria a órgãos da administração pública direta e indireta, empresas privadas e outras entidades; realizar vistorias perícias técnicas, laudos periciais informações e pareceres. 0 que delimita o caráter da atividade enquanto privativa do assistente social é a sua qualificação enquanto matéria, área unidade de Serviço Social (IAMAMOTO, 2012, p. 38)
Destarte, a interpretação de Terra (1998) acerca do inciso III do artigo $4^{\circ}$, articulando-o à noção de âmbito ou processo de utilização de métodos e técnicas do Serviço Social, como forma de enquadrar tal atividade como atribuição privativa, em nada resolveria o problema, visto que a área, o âmbito ou a matéria de que trata tal profissão não estão delimitados nos demais artigos do instrumento jurídico.

Todavia, os problemas são ainda maiores. Como se vê, as imprecisões não se restringem apenas aos dois incisos do artigo $4^{\text {a }}$ (competências), que, na visão da assessora jurídica do CFESS, deveriam compor 0 artigo $5^{\circ}$ (atribuições privativas), muito menos aos incisos $\mathrm{II}^{4}$ e VIII , também do artigo $4^{\circ}$, que se repetem quase que integralmente nos incisos I e III do artigo $5^{\circ}$. Esses elementos por si só já produzem um conjunto de dúvidas e confusões, pois, obviamente, uma atividade não pode ser ao mesmo tempo competência genérica, comum ao Serviço Social e a outras ocupações, e privativa, específica do Serviço Social - o fato de ser privativa evidencia que os indivíduos não detentores do diploma e registro de assistente social não estão aptos a executá-la. No entanto, pelo menos outros cinco (I, II, III, IV e XII) dos principais incisos do artigo $5^{\circ}$ estão completamente vazios de significado no que tange à regulamentação dos monopólios profissionais.

As demais atividades, como a fiscalização do exercício profissional, a supervisão de estagiários de Serviço Social, a elaboração de provas específi-

4. O inciso II do art. $4^{\circ}$ da Lei $8662 / 93$ estabelece como competência do assistente social "elaborar, coordenar, executar e avaliar planos, programas e projetos que sejam do âmbito de âmbito de atuação do Serviço Social com participação da sociedade civil”. Essas mesmas funções se repetem no inciso I do art. $5^{\circ}$ da mesma Lei, este abrangendo ainda supervisão, estudos e pesquisas: "coordenar, elaborar, executar, supervisionar e avaliar estudos, pesquisas, planos, programas e projetos na área de Serviço Social" (TERRA, 1998, p. 6)

5. O inciso VIII do art. $4^{\circ}$ da Lei $8662 / 93$ estabelece como competência do assistente social "prestar assessoria e consultoria a órgãos de administração pública direta e indireta, empresas privadas e outras entidades, com relação às matérias relacionadas no inciso II deste artigo". A mesma atividade está prevista no inciso III do artigo $5^{\circ}$, conforme já identificou Terra (1998, p. 9). 
cas para essa ocupação, a direção de equipes, bem como docência nas disciplinas que tratem da profissão, só poderiam realmente ser executadas por assistentes sociais. Isso não significa, porém, que a previsão legal seja desnecessária.

Mais do que um mero equívoco jurídico, as imprecisões da legislação têm gerado uma série de questões de ordem prática. Na introdução da brochura Atribuições privativas do Serviço Social em questão, lançada pelo CFESS em 2002, reeditada em 2012, justamente com o objetivo de ampliar a discussão sobre a Lei 8.662/93, a própria entidade constata, a partir dos registros e demandas das Comissões de Orientação e Fiscalização (COFIs) dos CRESS (Conselho Regional de Serviço Social), que os agentes fiscais têm encontrado dificuldades em fiscalizar, identificar e distinguir as competências e tarefas privativas dos assistentes sociais (CFESS, 2012, p. 23).

Entretanto, ao contrário do que sugere o CFESS (Idem) ao citar as considerações do CRESS $11^{\mathrm{a}} \mathrm{Re}$ gião, não cabe ao profissional individualmente resolver tais questões, do mesmo modo que a distinção entre o trabalho de um assistente social e o trabalho de um leigo não depende apenas da existência ou não de um projeto de intervenção. 0 fato de ser reconhecido e regulamentado como profissão subentende que determinadas necessidades são atendidas por essa categoria, que conquistou monopólios interventivos por demonstrar aptidão e qualidade no atendimento de certas demandas (FREIDSON, 1998). Nessa direção, mais do que fiscalizar se um leigo usa ou não o nome do Serviço Social, cabe aos conselhos fiscalizar e defender o exercício e as prerrogativas da categoria.

Ainda sobre os efeitos práticos decorrentes da estrutura do texto legal, é possível elencar as confusões entre objetivos, princípios, deveres, direitos e atribuições no conjunto dos profissionais (FELIPPE, 2013; CFESS, 2012; TORRES, 2007). A indefinição da legislação e a não identificação, por parte dos assistentes sociais, das funções por eles desempenhadas no corpo do texto podem contribuir para a não diferenciação entre as suas atividades e as realizadas por outros profissionais. Cabe também o registro da falta de clareza sobre os papéis e as distinções do Código de Ética, das legislações sociais e da Lei de regulamentação nas falas dos profissionais pesquisados pelos autores supracitados.

Nessa linha de raciocínio, fica evidente que os problemas e imprecisões da legislação do Serviço Social no Brasil são de ordem estrutural. Dessa sorte, em que pese às diferentes abordagens e posições sobre o assunto, dificilmente essa situação poderá ser resolvida com recursos interpretativos ou comentários como sugerem as abordagens que serão discutidas no item a seguir. Apesar disso, é possível mobilizar um conjunto de esforços na elaboração de resoluções e normativas propositivas por parte do Conselho Federal de Serviço Social, tendo como alvo amenizar certas dúvidas e incertezas no interior da profissão no tocante às tarefas desempenhadas pelos assistentes sociais.

\section{DIFERENTES ABORDAGENS ACERCA DA LEl $8.662 / 93$}

As dificuldades encontradas pelos agentes fiscais e pelo conjunto dos assistentes sociais na identificação de suas funções na Lei 8.662/93 levou um pequeno número de intelectuais da profissão a tecer considerações acerca deste instrumento jurídico. Seria pertinente dividir os poucos que assumiram tal desafio em três grupos de abordagens que merecem especial atenção.

No primeiro grupo, estão alocados pesquisadores e escritores que se posicionam no lugar comum de afirmação da referida legislação, declarando, com pouquíssimo grau de problematização, que "a lei atual acompanha o desenvolvimento da profissão no Brasil, estabelecendo com maior clareza princípios, competências e atribuições privativas" (TORRES, 2007, p. 51) ou que a Lei no $8662 / 93$ "orienta sobre 
área e matéria de Serviço Social, suas competências e atribuições privativas" (CAMARGO, 2011, p. 60).

É interessante notar que, a despeito da força de tais afirmações, esses autores não citam quais tarefas concretas são realmente executadas pelo assistente social e, primordialmente, quais são as atividades privativas dessa ocupação que estão regulamentadas juridicamente, apesar de ser esse o objetivo lançado pelos dois textos. Também chama a atenção o fato de as produções citadas confundirem os papéis da Lei 8.662/93 e do Código de Ética. Tanto Camargo (2011, p. 50 e 52) quanto Torres (2007, p. 51) informam que a referida regulamentação estabelece, além das competências e atribuições, os princípios e até os valores éticos.

Nessa linha, Torres (2007, p. 53) assevera que a defesa dos direitos sociais é estabelecida como uma prerrogativa para a efetivação do exercício profissional. Ora, os princípios e valores da categoria estão estabelecidos no Código de Ética e, de maneira alguma, a defesa de direitos pode ser compreendida como uma competência, muito menos como uma prerrogativa; trata-se novamente de um princípio, ou dever (art. $8^{a}$, alínea d), estabelecido no Código.

Não obstante, os resultados da pesquisa de Torres (2007, p. 50) demonstram que a maior parte dos assistentes sociais pesquisados ( $90 \%$, segundo a autora) também não reconhece a referida Lei de Regulamentação, confundindo-a com a LOAS (Lei Orgânica da Assistência Social) e/ou com o Código de Ética. A pesquisadora ainda relata que, conquanto estejam estabelecidas na legislação, os profissionais não visualizam suas atribuições privativas, inclusive alguns acreditam que sequer existem funções ou tarefas exclusivas do Serviço Social (Idem, p. 55). Essa falta de identificação por parte dos assistentes sociais entre 0 parâmetro legal e as tarefas executadas, bem como a indiferencialidade na comparação com as ações de outros técnicos, também já foi demonstrada na pesquisa de Felippe (2013). Entretanto, no caso de Torres (2007), pela rasa problematização sobre a estrutura do texto legal, afirmando-o de forma imperativa, as questões e as confusões são lançadas como problemas dos profissionais.

Outras produções poderiam ser encaixadas nesse primeiro grupo por citarem a Lei 8.662/93, sem, contudo, tecerem análises acerca da sua formatação. Todavia, essas duas autoras se destacam por terem escrito seus trabalhos com base nas pesquisas realizadas a partir das práticas concretas de assistentes sociais, comparando-as à Lei 8.662/93. Suas contribuições para a reflexão sobre a legislação, porém, são limitadas, restringindo-se à afirmação da aludida Lei.

Um segundo grupo de intelectuais (MOURÃO e PAIVA, 1998; IAMAMOTO, 2012) assume uma postura diferente: afirma a necessidade de uma maior atenção para a questão da regulamentação da profissão, percebendo que o texto legal precisa ser mais bem elucidado, já que, "na medida em que se propõe a delimitar a especificidade profissional do Serviço Social, reproduz algumas imperfeições e ambiguidades" (MOURÃO e PAIVA, 1998, p. 2). Entretanto, esses autores declaram que "não se trata aqui de propor uma nova lei, mas de desencadear um aporte coletivo de conhecimentos que possam contribuir na sua interpretação" (Idem, p. 2 e 3), corroborando com a apresentação do CFESS (2012, p. 24) ao propor que "dela não se depreende qualquer incorreção, mas, apenas, aprimorar a reflexão sobre o fazer profissional, de modo a qualificar a prática da fiscalização, podendo, até, acrescentar outros itens para ampliar ou esclarecer a interpretação".

O artigo lançado por Mourão e Paiva (1998) se destaca por ter sido o primeiro texto a abordar esse tema de forma crítica. As autoras, antes do parecer de Terra (1998), já identificaram alguns dos problemas que aqui foram listados: a dubiedade de sentidos entre os incisos dos artigos $4^{\circ}$ e $5^{\circ}$; a inclusão de certas atividades como competências, quando, historicamente, elas vêm sendo executadas como prerrogativas e o não esclarecimento sobre determinadas terminologias utilizadas no corpo do instrumento jurídico. 
Desta feita, na tentativa de oferecer alguma contribuição para a compreensão do texto legal, Mourão e Paiva (1998) afirmam a "questão social" como objeto ou matéria-prima da profissão ${ }^{6}$. Desse modo, definem que o campo de atuação do Serviço Social é "junto aos processos de redução das desigualdades sociais que submetem classes, grupos e indivíduos a situações de exclusão e de vulnerabilidade social" (Idem, p. 17). Para atender às necessidades sociais derivadas dessa matéria-prima, os assistentes sociais acionariam mecanismos correlatos às políticas sociais. Trabalhariam também na produção de novos valores éticos e na "desalienação".

Apesar de identificar alguns dos problemas da Lei 8.662/93, o ensaio das escritoras não consegue avançar na elucidação destes. Não fica absolutamente claro se os termos matéria, área e unidade na legislação podem ser definidos com base no conceito de "questão social" apresentado, nem a maneira como isso poderia ser expresso no corpo da Lei. De modo geral, apenas se estabelecem alguns elementos que ajudam a situar o mercado de trabalho do Serviço Social, vinculado às políticas sociais, benefícios e serviços voltados para a população que sofre os efeitos das desigualdades sociais - mercado este cada vez mais compartilhado com diversas outras categorias (psicólogos, advogados, pedagogos, entre outras).

Entrementes, de forma alguma essas constatações invalidam a contribuição apresentada, visto que apenas a identificação de imprecisões na regulamentação já é um dado importantíssimo para a época. As reflexões de Mourão e Paiva (1998) são, no entanto, claramente inspiradas nas obras de Marilda lamamoto, principalmente a vinculação entre a questão social e o Serviço Social. Antes de apontar as limitações dessa associação para a definição dos monopólios profissionais, serão apresentados os argumentos desta

\footnotetext{
6. Embora, para algumas correntes da teoria social, em especial a marxista, os termos matéria-prima e objeto não possam ser tratados imediatamente como sinônimos, nos trabalhos de Mourão e Paiva (1998) e lamamoto (2012), essas palavras são empregadas como possuidoras de uma significação. Para os fins deste estudo, serão mantidas as conceituações apresentadas por estas autoras.
}

última autora, os quais foram compilados na brochura lançada pelo CFESS em 2002 e reeditada em 2012.

Como importante representante da profissão e à convite do CFESS, lamomoto (2012) produziu um texto que trata do tema das atribuições privativas. Em tal trabalho, buscando responder aquelas inquietações identificadas na fiscalização dos CRESS, a autora se propõe a explicitar ou mesmo conceituar os termos matéria, área e unidade de Serviço Social, considerando que a qualificação teórica dessas palavras apontaria uma solução para a problemática.

As confusões e dubiedades derivadas da repetição de incisos e da alocação de possíveis prerrogativas no artigo que versa sobre as competências não são tratadas. Restringe-se a dizer que "as dúvidas relativas à interpretação legal do texto já foram elucidadas no Parecer Jurídico (TERRA, 1998) sobre o tema" (Idem, p. 37). Mesmo considerando que o documento referido abordou com certa profundidade alguns dos problemas inerentes à legislação, não se pode considerar a questão como resolvida.

A opinião técnica de um advogado não altera em nada o problema jurídico derivado da imprecisão da Lei, uma vez que a regulamentação federal de uma profissão sujeita não apenas os seus membros, mas também os empregadores e as demais ocupações. O mesmo não acontece no caso de uma resolução do conselho de categoria, por mais que esteja fundamentada num parecer técnico.

A título de exemplo, pode-se tomar mais uma vez o inciso XI do artigo $4^{\circ}$, que estabelece como competência do assistente social a realização de estudos socioeconômicos para inclusão em benefícios e serviços sociais. Essa tarefa, entendida como prerrogativa, mas regulamentada como atividade genérica, não está legalmente impedida de ser realizada por psicólogos, administradores, pedagogos ou ocupações de nível médio. Aliás, constantemente, outros profissionais vêm sendo convocados a realizar ações historicamente empreendidas pelo Serviço Social. 
Outro elemento a ser considerado é a criação de cargos genéricos que podem ser ocupados por assistentes sociais, embora não se caracterizem como cargo com exigência legal de atribuições privativas dessa profissão. Também tem ocorrido, em diferentes estados da federação, a criação de cargos/ocupações de nível médio, com atribuições que tangenciam aquelas da alçada do Serviço Social, conforme informações enviadas ao CFESS por alguns CRESS (CFESS, 2012, p. 18 e 19).

Voltando à proposta da professora em tratar os termos não elucidados no instrumento jurídico, percebe-se que a produção aqui analisada corrobora as suas formulações anteriores, nas quais o Serviço Social é relacionado à questão social. Dessa maneira, acredita lamamoto (2012, p. 38) que o esclarecimento sobre o significado das palavras área, matéria e unidade da profissão é uma questão "fundamentalmente da categoria, a quem cabe a sua explicitação".

As posições da autora não estão equivocadas, mas incompletas. Realmente cabe aos próprios assistentes sociais identificar a temática e o espaço em que sua intervenção se realiza. Entretanto, não são eles quem os definem sozinhos. Os monopólios e as jurisdições profissionais são estabelecidos na relação com o Estado, a sociedade e as demais profissões, a partir do conjunto de necessidades apresentadas socialmente. Por isso, esse não é um terreno simples, mas cercado de disputas e embates que envolvem o sistema profissional (DINIZ, 2001).

Logo, a compreensão dentro da trajetória intelectual da categoria sobre os papéis e as funções a que se dedicam os assistentes sociais é fundamental, mas não basta para assegurar os monopólios de prestação de serviços. É o primeiro passo a ser tomado, mas que deve ser expresso na legislação com o máximo de clareza possível (considerando todos os limites e historicidade de qualquer lei).

Prosseguindo com sua análise, lamamoto (2012, p. 39), fundamentada no dicionário Caldas Aulete, define matéria como a substância, assunto ou obje- to sobre o qual se exerce a força de um determinado agente; a área como o campo ou o âmbito de atuação da profissão; e a unidade como o conjunto de profissionais de um dado local de trabalho. Partindo disso, a escritora considera "o conjunto das expressões das desigualdades sociais engendradas na sociedade capitalista madura" (Idem, p. 48), a questão social, como o objeto ou matéria da profissão.

Se, como definiu a autora, as palavras em destaque são os elementos que permitem distinguir as atividades genéricas daquelas exclusivas da profissão (Idem, p. 38), como seria possível pensar a questão social ou as suas expressões como matéria do Serviço Social na legislação? Psicólogos, médicos, advogados e diversos outros profissionais também lidam com desigualdades sociais de classe, gênero, etnia e orientação sexual, não sendo tais desigualdades um tema abordado exclusivamente pelo Serviço Social. Nesse aspecto, as colocações de Faleiros (1997) são esclarecedoras.

Se for entendida [a questão social] como sendo as
contradições do processo de acumulação capitalis-
ta, seria, por sua vez, contraditório colocá-la como
objeto particular de uma profissão determinada,
já que se refere a relações impossíveis de serem
tratadas profissionalmente, através de estratégias
institucionais /relacionais próprias do próprio de-
senvolvimento das práticas do Serviço Social. Se
forem as manifestações dessas contradições o ob-
jeto profissional, é preciso também qualificá-las
para não colocar em pauta toda a heterogeneidade
de situações, que, segundo Netto, caracteriza, jus-
tamente, o Serviço Social (FALEIROS, 1997, p. 37).

Não se pretende adentrar na discussão teórica sobre os significados do conceito "questão social", pois isso extrapolaria as proposições deste trabalho, até porque, para uma regulamentação, é absolutamente impossível cristalizar uma matéria e uma área de atuação tão difusa e abrangente. A legislação se propõe a definir juridicamente determinadas atividades, as quais devem possuir um mínimo de precisão, como acontece no inciso XI do artigo $4^{\circ}$. 
A compreensão de tais elementos facilita a elucidação dos motivos que têm levado os assistentes sociais que trabalham em amplos projetos e em equipes interdisciplinares a não reconhecer suas funções como matéria ou atribuição do Serviço Social, conforme exemplo trazido por lamamoto (2012). Além das importantes mediações relacionadas à reestruturação produtiva, à construção de cargos genéricos e à polivalência exigida pelas empresas e pelo Estado aos funcionários, todos os trabalhadores da equipe lidam com o mesmo objeto (ainda que definido como "questão social"), embora possuam formações acadêmicas específicas, que os credenciam para a realização de determinadas atividades.

Esse processo, que é mutável e sujeito a redefinições, materializa as seguintes colocações de Mourão e Paiva (1998, p. 14): “há um lugar construído historicamente pela profissão, justificado pelo acúmulo de conhecimentos teórico-metodológicos e habilidades técnico-operativas, que capacitam o assistente social ao desempenho das funções previstas nos onze incisos, que compõem o texto legal". 0 fato de os profissionais não se identificarem como assistentes sociais pode, portanto, estar vinculado à situação de praticamente inexistirem prerrogativas dessa profissão, fazendo com que suas funções se diluam entre demais.

Nesse sentido, a compreensão do significado histórico, dos interesses políticos e econômicos que envolvem a institucionalização desse ofício e da dinâmica macrossocietária não resolve todos os dilemas sobre o papel e as ações profissionais. Para se assimilar o que faz o assistente social, é preciso investigar as práticas e o cotidiano dos agentes concretos, buscando identificar a sua especificidade em relação às demais ocupações - "aquilo que torna o exercício profissional diferente dos demais” (TORRES, 2007, p. 57). Importa registrar que a expressão especificidade é também utilizada pelos diferentes autores aqui citados (MOURÃO E PAIVA, 1998; TORRES, 2007; IAMAMOTO, 2012), evidenciando que
Não se pode confundir o debate sobre os espaços, atribuições e competências profissionais, tal como o aqui efetuado, com aquela noção de especificidade que esvazia o exercício profissional das relações sociais em que se realiza do contexto dos organismos empregadores, das relações e condições de trabalho e de suas implicações teóricas, metodológicas e éticopolíticas presentes no conteúdo e no processamento do trabalho (IAMAMOTO, 2012, p. 65).

As contribuições de lamamoto (2012) e Mourão e Paiva (1998), por mais que tenham avançado na abordagem do tema, inclusive com reflexão mais substanciais na comparação com o primeiro grupo, ainda são insuficientes para destrinchar todas as implicações derivadas da imprecisão legal. Nessa perspectiva, a negação da existência de limitações estruturais na Lei 8662/93 leva as escritoras a encarar erros e equívocos do texto como problemas de interpretação, impedindo o necessário movimento de reconstrução das prerrogativas do Serviço Social. Embora se reconheça que a atual conjuntura política ${ }^{7}$ não é a mais propícia para um novo projeto de lei, outras medidas administrativas e jurídicas (dentro do CFESS, por meio de resoluções propositivas, e do Ministério do Trabalho e Emprego, via Classificação Brasileira de Ocupações, por exemplo) poderiam ser levantadas na direção do fortalecimento e da construção de novos espaços de atuação, ao menos até que se reúnam aliados para a deflagração de um novo processo legislativo.

Considerando tais questionamentos, importa apropriar-se dos elementos oferecidos por um terceiro e pequeno grupo de intelectuais (FERNANDES, 2004; CARDOSO, 2005), que apresenta uma abordagem diferenciada ao afirmar claramente que "não há um delineamento concreto defensável de uma tarefa exclusiva. Isto porque ao se falar em matéria específica da profissão, abre-se uma gama de possibilidades para interpretações múltiplas" (CARDOSO, 2005, p. 59).

7. No dia 18 de novembro de 2014, por exemplo, a Presidência da República vetou o Projeto de Lei 3.338 de 2008 , que previa a redução da carga horária de psicólogos para $30 \mathrm{~h}$, sob alegação de impactos orçamentários. 
Nessa terceira linha de entendimento, os subsídios teóricos oferecidos por Cardoso (2005) são mais ricos se comparados aos de Fernandes (2004), visto que aquela se propõe a discutir o Serviço Social como profissão com base na sociologia de Eliot Freidson, ao passo que esta apenas cita as indefinições substanciais da referida Lei, por não ser esse o seu objeto de investigação.

De forma geral, no entanto, essas autoras identificam que a legislação atual apenas substituiu os termos prerrogativas e atribuições por competências e atribuições privativas, mas manteve as mesmas imprecisões do texto de 1957, como identificou Fernandes (2004, p. 84 e 85). Fundamentando-se nas palavras de Cardoso (2005, p. 67), essa ausência de delineamentos defensáveis de tarefas exclusivas condiciona diretamente a autonomia profissional, pois não permite evidenciar que "somente os possuidores daquele tipo de conhecimento especializado são capazes de julgar e avaliar o mérito dessas questões".

\section{CONSIDERACÕES FINAIS}

A imprecisão da legislação profissional possui efeitos complexos para a consolidação do Serviço Social num mercado de trabalho dinâmico e competitivo como o atual, sendo um dos elementos que contribuem indefinição do trabalho dos assistentes sociais na relação com outras ocupações (FELIPPE, 2013). Evidentemente, essas colocações não desconsideram que a construção das atribuições privativas e a sua regulamentação estão fundamentalmente determinadas pelas relações objetivas travadas no terreno social. Ao contrário, reitera-se que o processo de credenciamento responsável por assegurar o acesso monopolizado à realização de determinadas atividades apoia-se na relação entre as universidades, as associações profissionais e o Estado, fato já demonstrado no campo da sociologia das profissões (DINIZ, 2001; FREIDSON, 1998).
Nesse sentido, a abordagem do tema aponta para a necessidade de se repensar o processo de institucionalização e reconhecimento de um espaço legítimo e privativo de intervenção sobre o social, demonstrando que, na atualidade, apenas o nome Serviço Social está resguardado para os portadores de credenciais acadêmicas e registro nos quadros do Conselho. As atribuições e competências, contudo, permanecem abertas à execução por leigos.

\section{REFERÊNCIAS}

AURÉLIO, Buarque de Holanda Ferreira. $\boldsymbol{O}$ minidicionário da língua portuguesa. Rio de janeiro: Nova Fronteira, 2001.

BRASIL. Lei no 3.252 de 1957 regulamentada pelo Decreto 994 de 1962. Disponível em <http://www. planalto.gov.br/ccivil_03/bleis/L3252.htm>. Acesso em 04 de outubro de 2014.

BRASIL. Lei no 8.662 de 1993. Disponível em<http:// www.cfess.org.br/arquivos/legis lacao_lei_8662. pdf>. Acesso em 20 de setembro de 2013.

CAMARGO, Marisa. Atribuições privativas e competênciasdoassistentesocialnaatençãobásicaem saúde. Disponível em: <http://200.233.146.122:81/ revistadigital/in dex.php/debatesociedade/article/ viewFile/294/251>. Acesso em 09 de julho de 2012.

CARDOSO, D. A sociologia das profissões de Eliot Freidson: uma aplicação à análise do serviço social como profissão no Brasil. Dissertação (mestrado em Serviço Social) - Santa Catarina: UFSC, 2004.

CFESS. Atribuições privativas do assistente social em questão. Brasília: CFESS, 2012.

DINIZ, M. Os donos do saber: profissões e monopólios profissionais. Rio de Janeiro: Revan, 2001. 
FALEIROS, V. Estratégias em Serviço Social. São Paulo: Cortez, 1997.

FELIPPE, J. Projetos profissionais do Serviço Social e da Psicologia nos CRAS: uma articulação bem sucedida? In: Vértices. Campos dos Goytacazes: Essentia, v.15, n. 1, p. 97-111, 2013.

FERNANDES, N. A atuação do Conselho Regional de Serviço Social de São Paulo em relação às denúncias éticas: 1993 à 2000. Dissertação (mestrado em Serviço Social) - PUC SP. São Paulo: 2004.

FREIDSON, E. Renascimento do profissionalismo: teoria, profecia e política. São Paulo: EDUSP, 1998.

IAMAMOTO, M. Projeto Profissional, espaços ocupacionais e trabalho do(a) Assistente Social na atualidade. In: Atribuições privativas do assistente social em questão. Brasília: CFESS, 2012.
MOURÃO, A. M.; PAIVA, B. A. O serviço social como trabalho: uma contribuição ao debate sobre competências e atribuições profissionais. Brasília: CFESS, 1998.

NUNES, E.; CARVALHO, M. Ensino universitário, corporação e profissão: paradoxos e dilemas brasileiros. Sociologias. Porto Alegre, ano 9, n. 17, p. 190-215, 2007.

TERRA, S. Parecer jurídico $\mathbf{n}^{0}$ 27/98. Brasília: CFESS, 1998.

TORRES, M. Atribuições privativas presentes no exercício profissional do assistente social: uma contribuição para o debate. In: Libertas. Juiz de Fora: UFJF, v. 1, n. 2, p. 42-69, 2007. 